\title{
Jóvenes y política: una revisión de estudios desde latinoamerica
}

\section{Youth and politics: a review of studies from latin america}

\author{
Carlos Ramos-Galarza*, Diego Apolo-Buenaño**, Janio Jadán-Guerrero*** \\ * Facultad de Psicología. Pontificia Universidad Católica del Ecuador (PUCE). \\ ** Universidade Nacional de Educação do Equador (UNAE); Universidade de São Francisco de Quito (USFQ) \\ *** Centro de Investigación MIST. Universidad Tecnológica Indoamérica de Ecuador (UTI).
}

\begin{abstract}
Resumen
La percepción que los jóvenes tienen sobre la política en Latinoamérica se encuentra caracterizada por un desencanto y desinterés originado por la praxis de los políticos. La disociación que existe entre los discursos democráticos propuestos en campaña y el accionar mezquino en la ejecución de éstas, han creado en los jóvenes un alejamiento de la práctica formal de la política en la sociedad. Esta desilusión se reafirma cuando el joven experimenta las consecuencias políticas en los sistemas de atención a la sociedad, como es el caso de la negligencia dentro del sistema de salud, por poner un ejemplo. Otro factor que influye de forma negativa en la construcción política de la juventud es el contenido que se ofertan en los medios de comunicación. En el presente artículo se realiza una revisión de varios factores que han influenciado en la percepción del joven latinoamericano hacia la política. La metodología seguida se basó en la revisión de veinte y tres artículos indexados en las principales bases de datos Latindex, Redalyc, Scielo, JSTOR, SAGE, SCOPUS y WEB OF SCIENCE. Los términos de búsqueda utilizados fueron: política, juventud, percepción política de jóvenes latinoamericanos.
\end{abstract}

Palabras Clave: política, jóvenes, percepción, Latinoamérica.

Abstract

The perception that young people have about politics in Latin America is characterized by a disenchantment and disinterest caused by the praxis of politicians. The dissociation that exists between the democratic discourses proposed in the campaign and the petty action in the execution of these, have created in the young a departure from the formal practice of politics in society. This disappointment is reaffirmed when young people experience political consequences in systems of care for society, as is the case of neglect within the health system, to give an example. Another factor that negatively influences the political construction of youth is the content offered in the mass media. In the present article a review of several factors has been carried out that have influenced the perception of the young Latin American towards politics. The methodology used was based on the review of twenty-three articles indexed in the main databases: Latindex, Redalyc, Scielo, JSTOR, SAGE, SCOPUS and WEB OF SCIENCE. The search terms used were: politics, youth, political perception of Latin American youth.

Keywords: politics, youth, perception, Latin America.

\section{Introducción}

El ser un ciudadano es sentirse parte de la comunidad, es pertenecer a un sistema regido por una variedad de posturas políticas que influyen positiva o negativamente en su comportamiento diario. Ser ciudadano también implica identificar y hacer cumplir los derechos civiles, políticos y sociales, al igual que cumplir con los deberes y responsabilidades dentro de un medio social determinado (Martínez, 1999).

En dicho contexto, los jóvenes configuran su manera de relacionarse con los asuntos políticos, económicos y sociales; a la vez que adoptan un sistema de valores o una ideología que guía su accionar (Erikson, 1968). 
En Latinoamérica este sistema de valores se ha visto influenciado por los diversos modelos políticos y económicos, los cuales han dejado profundas huellas en la historia de los países de la región; que, en su gran mayoría, han sido marcados por crisis bancarias y sociales, además de un estilo de hacer política basada en la demagogia (Barcená, 1997).

Esta realidad ha generado desinterés, pesimismo y una postura de apatía a los aspectos políticos por parte de la juventud latinoamericana (Martínez, Silva, \& Hernández, 2010; Aguilar et al., 2015 \& Leyva, Muñiz \& Flores, 2016). Sin embargo, el desencanto de la juventud hacia la política no ha callado totalmente las ansias de expresión de los jóvenes, pues ésta es evidente en espacios no habituales, como lo son las calles y las plataformas digitales; por ejemplo, "las redes sociales están contribuyendo a la aparición de un nuevo modelo político" (Barredo, Arcila \& Barbosa, 2016, p. 227), las mismas que se han convertido en verdaderas vitrinas del pensamiento social (Díaz \& Salamanca, 2012; Ayala, 2014; Apolo, Guerrero \& Jiménez, 2015 \& Almansa-Martínez, 2016) dando lugar a "la existencia de una interpretación democrática más amplia" (Barredo, Oller \& Buenaventura, 2013, p. 80).

Así, "desde los años 90 del siglo pasado, candidatos y partidos políticos han venido utilizando las herramientas del ciberespacio como piezas importantes de su estrategia en campañas electorales" (Goulart \& Campos-Domínguez, 2016, p. 84). Pese a ello, una de las razones principales para que la juventud se haya desencantado por la praxis política, es su percepción de ésta como un entorno plagado de mentiras y palabrería, que son utilizadas para convencer a un grupo humano para que vote en favor de un candidato; quien, luego suele olvidar sus promesas y descuida a la ciudadanía que entrego su voto. Homedes \& Ugalde (2005) mencionan que esto puede verse reflejado, por ejemplo, en las reformas de salud neoliberales que se desarrollaron en los países latinoamericanos, donde los ciudadanos han sido dejados de lado, descuidados y utilizados como elementos mercantiles.

Un factor que ha influenciado notablemente en la construcción de los significados de la juventud en relación a la política, es el contenido propuesto por los medios de comunicación (Ruiz, 2015\& Aliaga et al., 2016), los cuales se han convertido en un instrumento de configuración de la opinión pública de jóvenes(Vera, 2005) y que en muchos casos, políticos están ligados a su manejo lo cual los convierte en un dispositivo de dominio y manejo de la información a merced de su conveniencia (Santillán, 2012).

Dentro de este contexto surge como objetivo de investigación, realizar una revisión de diversas fuentes de estudios empíricos y teorías que describan la actitud de los jóvenes en la política de Latinoamérica.

\section{Materiales y Métodos}

La metodología seguida consistió en la revisión sistemática de artículos indexados en las bases de datos principales que publican estudios realizados en Latinoamérica: Latindex, Redalyc, Scielo, JSTOR, SAGE, SCOPUS y WEB OF SCIENCE. De esta revisión se seleccionaron veinte y tres artículos que reportaron estudios realizados en Argentina, Chile, Colombia, México y Ecuador (Tabla 1). Los principales términos utilizados en la búsqueda fueron: política, juventud, percepción de la política de jóvenes latinoamericanos. 
Tabla 1: Principales aportes del estudio de los jóvenes latinoamericanos en la política latinoamericana

\begin{tabular}{|c|c|c|}
\hline Autor & Año & Aporte en la línea de investigación \\
\hline Zarzuri & 2008 & $\begin{array}{l}\text { Los jóvenes viven la política mediante prácticas no convencionales, donde } \\
\text { expresan su opinión desde la moda y lo comportamental. }\end{array}$ \\
\hline Díaz \& Salamanca & 2012 & Los jóvenes buscan espacios alternativos pa \\
\hline Kropff & 2011 & En los jóvenes Mapuches emerge un sentido de militantes de base. \\
\hline SENPLADES & 2011 & $\begin{array}{l}\text { En la política participan jóvenes pertenecientes a grupos tradicionalmente } \\
\text { marginados. }\end{array}$ \\
\hline Ayala & 2011 & Los jóvenes tienen pocas oportunidades en el ámbito político. \\
\hline Ramos \& Escobar & 2009 & Jación de los jóvenes en los procesos electorales es mí \\
\hline PNUD & 2008 & Los jóvenes ven a la democracia como inexistente. \\
\hline $\begin{array}{l}\text { Martínez, Silva \& } \\
\text { Hernández }\end{array}$ & 2010 & cial es realiz \\
\hline Almeida & 2002 & $\begin{array}{l}\text { El modelo neoliberal que prima en Latinoamérica quita oportunidades a los } \\
\text { jóvenes de grupos marginados. }\end{array}$ \\
\hline $\begin{array}{l}\text { Kornblit, Mendes, } \\
\text { DiLeo, Camarotti, } \\
\text { \& Adaszko }\end{array}$ & 2005 & $\begin{array}{l}\text { Los jóvenes evidencian la mala praxis política tradicional en los servicios que } \\
\text { recibe la sociedad, como por ejemplo, el de salud. }\end{array}$ \\
\hline $\begin{array}{l}\text { Homedes } \\
\text { Ugalde }\end{array}$ & 2005 & con la política de privatización. \\
\hline $\begin{array}{l}\text { Lucio, Villacrés \& } \\
\text { Henríquez }\end{array}$ & 2011 & El futuro de la sociedad se proyecta con mayores oportunidades para los jóvenes. \\
\hline Viteri & 2007 & $\begin{array}{l}\text { La mala atención de los servicios públicos de salud, son uno de los indicadores } \\
\text { para que los jóvenes tengan una percepción negativa sobre la política. }\end{array}$ \\
\hline $\begin{array}{l}\text { Aliaga, Basulto \& } \\
\text { Apolo }\end{array}$ & 2015 & $\begin{array}{l}\text { El contenido vacío de los medios de comunicación es la proyección de la mala } \\
\text { política para los jóvenes. }\end{array}$ \\
\hline Yanes & 2007 & La comunicación política sirve para manipular la opinión juvenil. \\
\hline Villa & 2012 & $\begin{array}{l}\text { Los personajes que aparecen en los programas televisivos influyen de forma } \\
\text { negativa en la construcción política juvenil. }\end{array}$ \\
\hline Checa-Godoy & 2012 & $\begin{array}{l}\text { Los medios de comunicación buscan mejorar la imagen de los políticos } \\
\text { tradicionales para buscar el voto de los jóvenes. }\end{array}$ \\
\hline Pastor & 2013 & $\begin{array}{l}\text { Los jóvenes entre } 15 \text { y } 29 \text { años de edad miran a la política como una práctica } \\
\text { para enriquecerse ilícitamente. }\end{array}$ \\
\hline Huabaquete & 2012 & $\begin{array}{l}\text { Los jóvenes de género femenino participan dentro de cargos políticos y en el } \\
\text { trabajo por comunidades y pueblos. }\end{array}$ \\
\hline
\end{tabular}

Fuente: Elaboración propia. 


\section{Resultados}

Los hallazgos encontrados en los diversos artículos analizados se los englobaron dentro de categorías que permitieron tratar cada uno de los contenidos que emergieron en la investigación. En la figura 1 se puede observar la organización gráfica de las categorías.

Figura 1: Categorías emergentes en el análisis de contenido

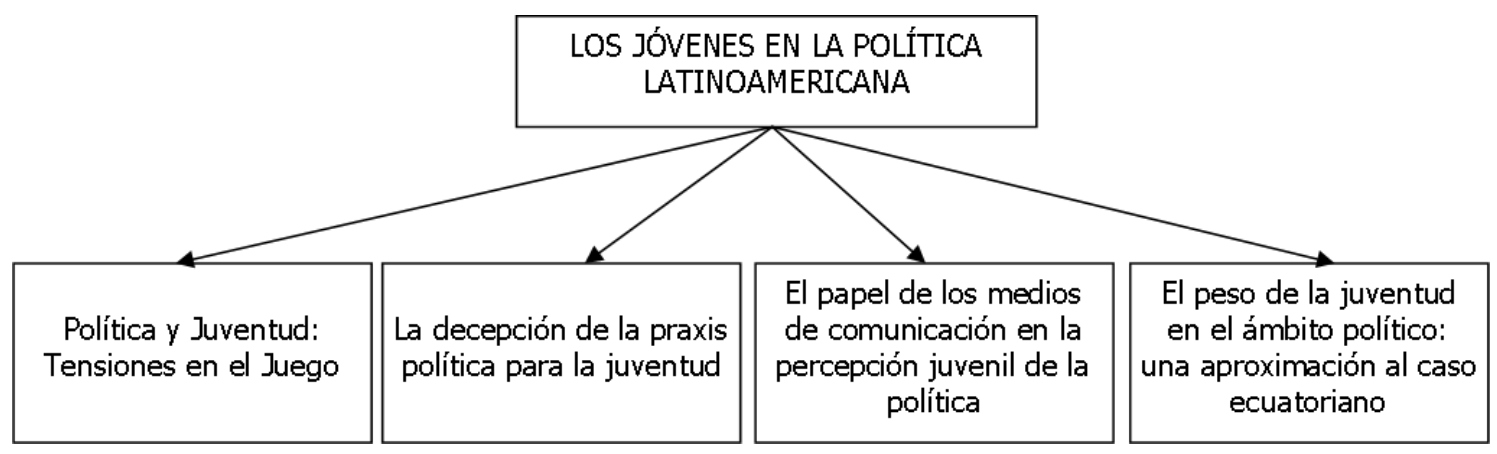

Fuente: Elaboración propia.

\section{Política y Juventud: tensiones en juego}

Para Zarzuri (2008) los jóvenes conciben la praxis política dentro de los parámetros que se han desarrollado desde su cotidiano, donde realizan una resistencia a las normas sociales, a través de rituales caracterizados por el uso de una vestimenta de estilo extraño, actitudes bizarras, incumplimiento de los códigos de etiqueta; haciendo evidente su desafío y malestar ante la incomprensión social a la que se sienten sometidos. Según un estudio sobre los jóvenes como sujetos políticos, realizado en Colombia por Díaz \& Salamanca (2012), se indica que este grupo social presenta una pluralidad de formas de hacer política, la cual es vivenciada desde espacios informales y tradicionales, los cuales, van desde movilizaciones y resistencias violentas, hasta la organización de eventos que brindan prioridad al debate tradicional para plasmar su voz cuando tienen una postura diferente a la establecida.

Además, Díaz \& Salamanca (2012) reconocen la existencia de tres tendencias en la concepción de la política por parte de los jóvenes: como acción normativa, como solidaridad y como negatividad. De manera que, los jóvenes sí tienen una participación política, la cual se desarrolla desde sus múltiples maneras y esferas de interacción, que no siempre es percibida como legítima desde la normatividad formal de la política clásica. En Argentina, Kropff (2011) realizó un análisis de la postura política de jóvenes Mapuche, donde describe que, en el quehacer político del grupo estudiado, se reconoce y elige definirse como militantes de base, en vez de actores políticos; ya que, la militancia tiene relación con la reflexión sobre su identidad, su cultura, historias y tradiciones familiares, más allá de un discurso demagógico que desvincula las posibilidades de cambiar la realidad de dicho país. 
En Ecuador, la Secretaria Nacional de Planificación y Desarrollo (SENPLADES, 2011) describe que la práctica política de los jóvenes se presenta dentro de un contexto informal; los jóvenes entre 17 y 24 años manifiestan su malestar ante la política del país en prácticas como la realización de grafitis, envío de mensajes políticos a través de internet, evitando comprar ciertos productos por razones éticas o políticas, y manifestaciones en las calles. Además, este estudio la indica que la participación política de los jóvenes se presenta en mayor porcentaje en hombres que en mujeres. Según la etnia, participan más jóvenes mestizos seguidos por blancos y en menor proporción afro ecuatorianos e indígenas.

Según Ayala (2011), lamentablemente, la realidad que vive Ecuador no refleja ese constructo de ideal social, siendo más bien, una realidad en la cual los jóvenes entre 18 y 29 años poseen pocas oportunidades sociales, esto en gran medida a que la oferta política tradicional del gobernante ecuatoriano, es la de hablar mucho e invertir poco, lo cual ha ido transformándose desde el imaginario y las políticas impulsadas por el gobierno de Rafael Correa desde el 2007.

En el contexto mexicano, Ramos \& Escobar (2009) reportan un estudio en el cual afirman que la participación político-electoral voluntaria de los jóvenes de dicho país es cuantitativamente poco significativa; ya que, la praxis política y las instituciones alrededor de ésta son poco o nada atractivas para los jóvenes mexicanos. Esta no credibilidad surge de la demagogia de los políticos de dicho país, quienes realizan ofrecimientos en las campañas electorales que los convierten en actores sociales desfasados en el tiempo, insuficientes a las expectativas juveniles e ineficaces en el cumplimiento de objetivos que generan que los temas políticos no sean atractivos para la juventud.

En Perú, un estudio desarrollado por el Programa de Naciones Unidas para el Desarrollo del Perú - PNUD (2008), menciona que la mayoría de jóvenes consideran que la representación política tiene un mal funcionamiento, incluso, indican que dudan o niegan la existencia de la democracia. Los jóvenes de este país, al igual que en el resto de Latinoamérica, comparten el desencanto a la política por situaciones como la inequidad social que se expone en todos los ámbitos de la sociedad peruana. Además, se indica que los jóvenes muestran desilusión ante sus líderes políticos y un anhelo por cambiar la realidad política experimentada en el país.

Para los jóvenes chilenos, la motivación central hacia la política, según Martínez et al. (2010), es la de una renovación de la sociedad que ataña, sobretodo, el respeto a los derechos de las personas en el sistema político, debido a las injusticias, inequidad y falta de poder y voz desde los ciudadanos. Además, otro aspecto que se resalta en la praxis política de los jóvenes chilenos, es la denuncia que realizan a las fallas en el sistema social, que genera que las personas sean vulneradas en sus derechos. En tal sentido, los jóvenes chilenos "señalan que hay vidas coartadas porque «todo se compra» y quien no tiene poder de compra queda excluido" (p. 30).

\section{La decepción de la praxis política para la juventud: el sistema de salud}

Almeida (2002) afirma que producto de las crisis sociales que se generaron en las últimas tres décadas del siglo pasado en los países latinoamericanos desde los enfoques neoliberales, es que se realizaron cortes importantes en el gasto público, donde una de las áreas más afectadas fue el servicio de salud, el cual se encuentra bajo una perspectiva economicista, pragmática y restrictiva; lo cual, construye una realidad en 
donde el que tiene dinero es capaz de pagar su atención médica, produciendo inequidad entre los individuos que componen el sistema social.

Según Kornblit et al. (2005) los jóvenes argentinos se sienten desprotegidos por el sistema de salud local. Además, en Argentina el acceso al sistema de atención de salud está condicionado por factores geográficos, económicos y sociales, que limitan y restringen la oportunidad de alcanzar el servicio médico oportuno. Homedes \& Ugalde (2005) afirman que el gran desencanto de la política relacionada al sistema de salud surge en la época de los ochentas cuando se inició en América Latina el proceso de privatización de la salud, situación que en países como Chile y México se mantienen hasta la actualidad.

En Chile, los jóvenes describen que las políticas de salud pagada hacen que se genere una atención no equitativa a todas las personas en el país, considerando así, al sistema de salud como injusto, mercantilizado y que se vende al individuo que tiene dinero; además que los políticos hacen las leyes que las empresas privadas de salud necesitan para seguir tratando a la atención médica como uno de los principales mercados de lucro (Martínez et al., 2010).

Según Lucio, Villacrés \& Henríquez (2011) existe una realidad diferente en Ecuador; ya que, en los últimos 5 años se han generado cambios importantes, no suficientes, pero han permitido cambiar la postura de atención en salud al ser humano desde un enfoque del Buen Vivir centrado en la calidad y calidez. Dentro de los aportes más relevantes se destacan la incorporación en la Constitución de la República del Ecuador (2008) un capítulo que reconoce a la protección de la salud como un derecho humano, la construcción de una Red Pública Integral de Salud, el Aseguramiento Universal de Salud y la adopción de una política pública que afirma que el derecho al acceso a medicamentos debe anteponerse al derecho de propiedad intelectual. Viteri (2007) indica que, si bien es cierto, en el transcurso de los últimos años se ha apreciado un mejoramiento de las condiciones del sistema de salud en el Ecuador, éste todavía presenta la desilusión juvenil que se basa en la percepción de las elevadas tasas de mortalidad neonatal, infantil, materna y en la generalidad de la población; además, indica que existen deficiencias en lo concerniente a infraestructura, equipamiento, talento humano y una limitación en los presupuestos del sistema de salud del país.

Existen diversos factores que influyen en el desencanto hacia la política por parte de los jóvenes y se ha dejado sobre la mesa su percepción construida en relación al sistema de salud. Sin embargo, en este sentimiento juvenil concurren otros factores influyentes como son los medios de comunicación que generan o manipulan la información que este grupo social recibe (Santillán, 2012).

\section{El papel de los medios de comunicación en la percepción juvenil de la política}

García (2004) es contundente en afirmar que la mayoría de productos audiovisuales considera a la juventud como un conglomerado sin una postura filosófica que realice una crítica a lo que recibe del medio de comunicación, a más de ser, la televisión, un instrumento desculturizante que entretiene de forma ligera y donde todo su contenido tiene un valor mercantil. Contexto en el cual, incluso la política se vuelve parte de un reality show, donde el quehacer ciudadano político se vuelve un aspecto cómico y superficial de la sociedad, sin tomar en cuenta, que muchas veces las prácticas de los jóvenes son confinadas hacia la invisibilidad y construcción de un imaginario negativo ante este grupo social (Aliaga, Basulto \& Apolo, 2015). 
Tal fue el caso de las últimas elecciones políticas en Ecuador, en donde existió un gran número de personalidades de la televisión, modelos, animadores, futbolistas, cantantes entre otros que buscaron una plaza en los diferentes estamentos políticos del país (El Comercio, 2017).

Retomando los aportes de Santillán (2012), describe que en México los medios de comunicación tienen un poder importante en los procesos de elección política, que se caracteriza por responder a intereses ideológicos y económicos de la empresa privada, que mediante la información que difunden influyen en el conocimiento del telespectador y sobre lo que este percibe de su realidad política.

Según Yanes (2007), "la comunicación política utiliza la persuasión como arma para convencer a la opinión pública sobre un determinado planteamiento" (p. 355). De manera que, los elementos políticos y de persuasión se convierten en armas inseparables; ya que, la información en la praxis política jamás carece de intencionalidad y busca generar una tendencia marcada en favor del candidato o partido del grupo de poder.

En Colombia se afirma que existe preocupación por el contenido televisivo relacionado con la política que recibe la audiencia juvenil; en tal sentido, Villa (2012) propone que los directores de los diferentes programas televisivos deben ser conscientes sobre la influencia que ejercen los personajes de pantalla; ya que, estos constituyen referentes para los jóvenes que los siguen. Por tal razón, el vestuario, lenguaje, valores y responsabilidad ante la problemática social son aspectos que deberían ser tomados en cuenta al momento de producir los programas dirigidos a los jóvenes, aunque desde los consumos que estos realizan, no consideran relevantes estos aspectos al momento de su elección.

Por otra parte, Martínez et al., (2010) afirman que la percepción de los jóvenes chilenos considera a los medios de comunicación como un instrumento que menoscaba la pobreza dentro de los contenidos que oferta al público, además de la "tristeza" de su realidad y sus problemas sociales asociados: embarazo adolescente, drogadicción, delincuencia o la desprotección en la familia. En los medios de comunicación se vive una realidad alterna a la sociedad que existe en las calles de dicho país. En la praxis de los medios de comunicación de Ecuador se vive un panorama similar. Según Checa-Godoy (2012) la prensa, radio y televisión ecuatoriana han generado campañas de mejoramiento de la imagen de actores y la revisión de eventos que han sido marcados por la corrupción, en donde la mayoría de las veces, de los mismos individuos de quienes se habla, son quienes dirigen los medios de comunicación y cabe mencioar su importancia tomando en cuenta que "los medios tradicionales están cayendo en la circulación y la credibilidad, todavía juegan una gran parte de cómo la gente se orienta en el mundo" (Karlsson, 2016, p. 152)

Llegado a este punto surgen varias interrogantes, por ejemplo, qué papel cumple la juventud en la toma de decisiones de un país, qué relevancia tienen los jóvenes en el contexto político o si son tomados en cuenta en alguno de los niveles del quehacer político.

\section{El peso de la juventud en el ámbito político: una aproximación al caso ecuatoriano.}

Según Pastor (2013) en el Ecuador los jóvenes entre 15 y 29 años de edad son indiferentes a la participación política partidaria. Esta realidad se explica en gran medida a la falta de espacios de expresión de política legítima para los jóvenes, los innumerables casos de corrupción que identifican al político como un individuo 
que se enriquece a costa de la mayoría de ciudadanos de un sistema social, causando una falta de compromiso solidario, que engloban características a las cuales un joven no desea para nada acercarse.

Según la SENPLADES (2011) en los últimos años la juventud ha elevado su participación política informal; es decir, protestas en las calles ante los gobiernos injustos y según los datos proporcionados por este organismo estatal, los jóvenes entre 17 y 24 años han ido aumentando progresivamente su presencia en las manifestaciones para las caídas de los gobiernos de Bucaram, Mahuad y Gutiérrez.

Una de las justificaciones para este fenómeno, se origina en que la organización de las acciones para la caída del presidente Lucio Gutiérrez (evento de mayor trascendencia política en los jóvenes ecuatorianos) se dieron sin la participación de los partidos políticos o actores políticos tradicionales; las protestas se dieron a través de la convocatoria, por iniciativa propia de los jóvenes, en programas radiales, a través de celulares e internet, donde se crearon nuevas formas de convocatoria y alternativas nunca antes vista en las protestas contra el gobierno que terminó sucumbiendo ante la manifestación social. Un aspecto que llamó la atención es que los jóvenes protestantes atrajeron a más jóvenes que se unieron a las protestas en una especia de técnica de muestreo por bola de nieve (De la Torre, 2006).

En el Ecuador se ha dado un importante giro en cuanto a la participación de los jóvenes en los cargos políticos públicos del país. Un ejemplo de aquello son las contrataciones realizadas por el gobierno en el 2014, en donde se incorporó a un alto número de jóvenes profesionales en empresas públicas como Petroamazonas o la Secretaría de Educación Superior; además, se indica que se ha enviado a trabajadores jóvenes a especializarse en el extranjero para el manejo de los recursos del país. Los jóvenes que han tenido mayor oportunidad para el ingreso al medio laboral público se encuentran en el rango de edad de 22 a 30 años (El Ciudadano [b], 2014).

En cuanto a la intervención política de la mujer joven en el contexto ecuatoriano, Huambaquete (2012) propone que ésta se la observa en tres niveles de participación desde la política formal hasta la integración comunitaria (Tabla 2).

Tabla 2: Niveles de participación femenina en el contexto ecuatoriano

\begin{tabular}{|l|l|l|}
\hline (1) participación política & (2) participación ciudadana & (3) participación comunitaria \\
\hline Mujeres que ya ocupan cargos & Mujeres jóvenes y lideresas & Mujeres representantes de \\
públicos en diferentes espacios & aportan a la generación de políticas & organizaciones indígenas y de la \\
del gobierno. & públicas en sus diferentes campos \\
& de acción. & $\begin{array}{l}\text { sociedad civil que efectúan un } \\
\text { trabajo por sus comunidades y } \\
\text { pueblos. }\end{array}$ \\
\hline
\end{tabular}

Fuente: Elaboración propia.

Actualmente, en Ecuador los cargos políticos se caracterizan por estar ocupados por un importante número de jóvenes, lo cual es un acontecimiento nunca antes visto en la historia gubernamental. El 30\% de estos cargos políticos que dirigen el país está en manos de jóvenes mujeres ecuatorianas, además de tres mujeres jóvenes que se encontraban al mando de la Asamblea Nacional del Ecuador desde el 2013 hasta el 2017, de las cuales, la edad de su presidentaera de 31 años (Andes, 2013).

Otro indicador afirma que el área económica ecuatoriana está a cargo de jóvenes académicos menores de treinta y seis años de edad, quienes ostentan títulos de doctorado y maestría. Un aspecto interesante es 
que estos jóvenes políticos no fueron parte de los partidos políticos que quebraron al Ecuador en años pasados. Sin embargo, esta realidad es criticada por los políticos de edad adulta que afirman que en el pasado el país contaba con ilustres ministros y legisladores con experiencia en el mandato y no por jóvenes sin una historia política que pueda beneficiar al rumbo del país (El Ciudadano [a], 2014).

\section{Conclusión}

El presente artículo ha realizado un análisis de la perspectiva de los jóvenes latinoamericanos en relación a la política. Se ha partido describiendo que el joven de Latinoamérica presenta una praxis política caracterizada por expresarse de forma mayoritaria en escenarios informales.

En dichos contextos es usual que el joven exprese su ideología política a través de su apariencia, envío de mensajes por internet, grafitis y manifestación en las calles que dejan en claro que, desde su postura, no comparten la misma doctrina establecida o su rechazo a la política que dirige a su país. En referencia a la praxis formal, se ha descrito que los jóvenes organizan eventos de debate en donde expresan su discurso y posición política.

En varios países de Latinoamérica los jóvenes expresan su descontento en relación a la política, ya que su desencanto ha ido construyéndose y reforzándose con la inmensa cantidad de discursos demagógicos, desfasados de tiempo, ineficaces e ineficientes de los políticos de las elites de los países latinoamericanos. En tal sentido, los jóvenes más bien buscan una militancia de base, en vez de ser políticos que ofertan lo incumplible; ya que, esta afiliación se relaciona directamente con la realidad en la que viven y en las posibilidades verdaderas de cambiar el sistema social en el cual se desenvuelven.

En la participación político-electoral voluntaria de los jóvenes se afirma que esta es poco significativa, ya que el desencanto ante los políticos de siempre, hace que la juventud muestre poco o ningún interés ante este tipo de acontecimientos de elección de autoridades.

La inequidad social aumenta la decepción de los jóvenes ante las políticas gubernamentales, ya que los políticos crean leyes y espacios en los cuales refuerzan la dominación y el capitalismo que generan amplias brechas sociales entre los que tienen posibilidades económicas y los desprotegidos de la sociedad. Sin embargo, este factor de inequidad a la vez es fuente de motivación para el enrolamiento de los jóvenes en el medio político, ya que el principal anhelo del joven es crear un sistema social justo y con oportunidades para todos los actores que lo componen.

Un punto importante que influye en la percepción política de los jóvenes es la atención que se brinda a la comunidad en general en diversas responsabilidades públicas, entre las cuales resalta el sistema de salud. En tal contexto se ha expuesto que el acceso a la atención sanitaria en Latinoamérica se ha caracterizado por ceder espacio a la empresa que mercantiliza la medicina para el ser humano, en donde quien tiene dinero puede acceder al pago de su salud.

Este sistema sanitario ha generado que los jóvenes tengan la percepción de que, desde las políticas gubernamentales no se hace algo para que disminuya la atención médica injusta y mercantilizada.

A nivel local se afirma que han existido mejoras en el sistema de salud, sin embargo, no han sido suficientes ante la alta demanda de infraestructura, equipamiento, personal profesional y presupuesto para conseguir el sistema de salud óptimo a las necesidades de la sociedad demandante de dicho servicio. 
Otro factor analizado es el papel de los medios de comunicación en la percepción de los jóvenes sobre la política (ver figura 2).

Figura 2: Papel de los medios de comunicación

\begin{tabular}{|l|l|l|l|}
\hline $\begin{array}{l}\text { Un elemento } \\
\text { deformante de la } \\
\text { cultura }\end{array}$ & $\begin{array}{l}\text { Instrumento de } \\
\text { comunicación que } \\
\text { presenta lo que } \\
\text { responde a los } \\
\text { intereses } \\
\text { económicos de sus } \\
\text { propietarios }\end{array}$ \\
\hline
\end{tabular}

Fuente: Elaboración propia.

En un último elemento analizado se caracteriza al peso que tiene la juventud en el ámbito político. A nivel local se ha reportado que los jóvenes entre 15 y 29 años han aumentado su participación política espontánea y sin influencia de los políticos clásicos del país. Esto se ha podido plasmar en la caída popular del gobierno de Gutiérrez, en donde la juventud tuvo un papel trascendental en la consecución de los objetivos sociales de un cambio político.

Si bien se ha descrito un número importante de estudios que han analizado la situación de los jóvenes ante la política latinoamericana es necesario continuar adentrándose en las doctrinas de este grupo humano ante el contexto político actual, por ejemplo, es necesario analizar la perspectiva hacia la política de jóvenes pertenecientes a grupos revolucionarios que buscan una equidad social, de igual manera, es necesario adentrarse en los constructos políticos de los jóvenes involucrados en partidos políticos de derecha y extrema derecha. En fin, nos encontramos en un contexto en el cual existe un importante campo para seguir investigando y aportando para construir una mejor sociedad.

Se termina el presente artículo con la mención del alto número de jóvenes que actualmente se encuentran a cargo de altos mandos políticos de Ecuador, en donde el papel de la joven mujer ha sido cada vez más influyente. Sería importante dentro de unos años poder contrastar si el peso de la juventud considerado hoy por hoy como bajo, ver cómo se mantuvo, y apreciar si sus decisiones lograron enrumbar acertadamente al país y no se trate de algún nexo político que haga que su papel en la dirigencia sea por influencia y no por verdaderos méritos y sentimientos nobles hacia la política del país.

Como línea de investigación futura nos proyectamos a la realización de una investigación empírica en la cual se identifiquen las narrativas que se construyen en los jóvenes de Ecuador en referencia a las actuales formas de hacer política en el país y, en una siguiente fase, mediante una metodología de investigación acción participativa, realizar una intervención para aportar en el sentido crítico de los jóvenes hacia la política del país. 


\section{Referencias}

Aguilar, Y., Valdez, J., González, N., Rivera, S., Carrasco, C., Gómora, A., Pérez, A.,\& Vidal, S. (2015). Apatía, desmotivación, desinterés, desgano y falta de participación en adolescentes mexicanos. Enseñanza e Investigación en Psicología, 20, 326-336. En: <http://www.redalyc.org/articulo.oa?id=29242800010>. Última consulta: 16 de mayo de 2017.

Aliaga, F. Basulto, O. \& Apolo, D. (2015). "Reacciones sociales e invisibilidad mediática frente al imaginario del joven problema". En Diálogos sobre juventud en Iberoamérica. Basulto, O. y Aliaga, F. (Coords.) 14-31. Santiago de Compostela, España: Universidad de Santiago de Compostela, Servicio de Publicaciones.

Aliaga, F., Apolo, D., Carretero, E. \& Cusot, G. (2016). La articulación entre comunicación política, imaginarios y emociones: un acercamiento a la Revolución Ciudadana en Ecuador. ComunicologiaRevista de Comunicação e Epistemologia da Universidade Católica de Brasília, 9(2), 150-163. En: https://portalrevistas.ucb.br/index.php/RCEUCB/article/view/6693.

Almansa-Martínez, A. (2016). Estudio sobre la participación de estudiantes universitarios en la vida política. Opción, 32(7), 39-54. En: <http://www.redalyc.org/pdf/310/31048480006.pdf>. Última consulta: 23 de mayo de 2017.

Almeida, C. (2002). Reforma de sistemas de servicio de salud y equidad en América y el Caribe. Algunas lecciones de los años 80 y 90. Cuadernos de Saúde Pública, 18(4), 905-925. En: <http://www.scielo.br/scielo.php?pid=S0102311X2002000400002\&script=sci_abstract\&tlng=es>. Última consulta: 12 de junio de 2017.

Andes. (2013). Una joven política preside la Asamblea Nacional Legislativa del Ecuador. Quito.En: <http://www.andes.info.ec/es/actualidad/gabriela-rivadeneira-primera-mujer-presidenta-historiaasamblea-nacional-ecuador.html> Última consulta: 02 de abril de 2017.

Ayala, P. (2011). Políticas Públicas sobre Juventud en Ecuador desde 1980. Procesos, 34 (2), 125-144. En: <http://revistaprocesos.ec/ojs/index.php/ojs/article/view/56/76>. Última consulta: 30 de marzo de 2017.

Ayala, T. (2014) Redes sociales, poder y participación ciudadana. Revista austral de ciencias sociales,(26), 23-48. En: <http://www.redalyc.org/pdf/459/45931862002.pdf>. Última consulta: 24 de febrero de 2017.

Apolo, D., Guerrero, S., \& Jiménez, S. (2015). Comunicación digital y política: aproximaciones para su gestión. Redmarka: revista académica de marketing aplicado, (15), 3-22. En: <http://redmarka.net/ra/doc.php?n=1969> Última consulta: 01 de junio de 2017.

Barcená, F. (1997). El oficio de la ciudadanía: introducción a la educación política. Barcelona, España: Paidós.

Barredo, D., Oller, M. \& Buenaventura, S. (2013). The End of the Information Society. Notes for the Configuration of the New Contemporary Public Space: the Society of Devisers. Observatorio (OBS*), 7(3), 79-91. En: <http://obs.obercom.pt/index.php/obs/article/view/647/618>. Última consulta: 24 de abril de 2017.

Barredo, D., Calderón, C. A., \& Barbosa, E. (2016). El perfil de los usuarios de Twitter más influyentes en Ecuador y la influencia del mensaje en la captación de seguidores. Observatorio (OBS*), 10(4), 
219-230. En: <http://obs.obercom.pt/index.php/obs/article/view/1004/pdf>. Última consulta: 24 de mayo de 2017.

Checa-Godoy, A. (2012). La Banca y la propiedad de los medios: el caso de Ecuador. Revista Latina de Comunicación Social, (67), 125-147. En: <http://www.redalyc.org/articulo.oa?id=81923566011>. Última consulta: 11 de marzo de 2017.

Constitución de la República del Ecuador. (2008). Registro Oficial No. 44920 de octubre de 2008, Ciudad Alfaro: Asamblea Constituyente. En: <http://www.asambleanacional.gob.ec/sites/default/files/documents/old/constitucion_de_bolsillo. pdf $>$. Última consulta: 24 de abril de 2017.

De la Torre, C. (2006). Populismo, democracia, protestas y crisis políticas recurrentes en el Ecuador. Análisis e informaciones. Rio de Janeiro, Brasil: Fundación Konrad Adenauer.

Díaz, A., \& Salamanca, L. (2012). Los jóvenes son sujetos políticos... a su manera. Utopía y Praxis Latinoamericana, 17 (57), 109-117. En: <http://www.redalyc.org/pdf/279/27922814010.pdf>. Última consulta: 29 de marzo de 2017.

El Ciudadano. (2014 a). Gabinete ministerial de la Revolución Ciudadana es el más joven y preparado de la historia. Quito. En: <http://www.elciudadano.gob.ec/gabinete-ministerial-de-la-revolucionciudadana-es-el-mas-joven-y-preparado-de-la-historia>. Última consulta: 09 de abril de 2017.

El Ciudadano. (2014 b). Jóvenes profesionales ecuatorianos integran las empresas públicas del Ecuador. Quito. En: <http://www.elciudadano.gob.ec/jovenes-profesionales-ecuatorianos-integran-lasempresas-publicas-del-ecuador>. Última consulta: 09 de abril de 2017.

El Comercio. (2017). Adelante ecuatoriano Adelante presentó a sus candidatos en Pichincha. Quito. En: <http://www.elcomercio.com/actualidad/presentacion-candidatos-adelanteecuatorianoadelantepichincha-caravan.html>.Última consulta: 15 de marzo de 2017.

Erikson, E. (1968). Identidad, juventud y crisis. Buenos Aires, Argentina: Paidós.

García, L. (2004). Juventud y medios de comunicación. La televisión y los jóvenes: aproximación estructural a la programación y los mensajes. Ámbitos, 11 (1), 115-129. En: <https://www.ull.es/publicaciones/latina/ambitos/11-12/archivos11_12/reina.pdf>. Última consulta: 03 de marzo de 2017.

Goulart, M., \& Campos-Domínguez, E. (2016). Elecciones de Brasil en 2014: las webs de los candidatos presidenciales como herramienta de campaña electoral. Observatorio (OBS*), 10(1), 83-106. En: <http://obs.obercom.pt/index.php/obs/article/view/901>. Última consulta: 29 de marzo de 2017.

Homedes, N., \& Ugalde, A. (2005). Las reformas de salud neoliberales en América Latina: una revisión crítica a través de dos estudios de caso. Revista Panamericana de Salud Pública, 17 (3), 210-220. En: <http://www.scielosp.org/pdf/rpsp/v17n3/a12v17n3.pdf>. Última consulta: 30 de marzo de 2017. Huambaquete, I. (2012). Mujeres en la política y en el ejercicio del poder. Agora Política, 6, 56-58.

Karlsson, M. (2016). Goodbye politics, hello lifestyle Changing news topics in tabloid, quality and local newspaper websites in the UK and Sweden from 2002 to 2012. Observatorio (OBS*), 10(4). En: <http://obs.obercom.pt/index.php/obs/article/view/940>. Última consulta: 07 de marzo de 2017.

Kornblit, A., Mendes, A., DiLeo, P., Camarotti, A., \& Adaszko, D. (2005). Salud y enfermedad desde la perspectiva de los jóvenes. Un estudio en jóvenes escolarizados de la Ciudad de Buenos Aires. Buenos Aires, Argentina: Instituto de Investigaciones Gino Germani. 
Kropff, L. (2011). Debates sobre lo político entre jóvenes mapuche en Argentina. Revista Latinoamericana de Ciencias Sociales, Niñez y Juventud, 1 (9), 83-99. En: $<$ http://biblioteca.clacso.edu.ar/Colombia/alianza-cindeumz/20140402112244/art.LauraKropff.pdf>. Última consulta: 12 de abril de 2017.

Leyva, O., Muñiz, C. \& Flores, M. (2016). La conformación de actitudes políticas de los jóvenes universitarios en el contexto preelectoral 2015 en Nuevo León. Revista mexicana de opinión pública, (21), 51-70. En:<http://www.scielo.org.mx/scielo.php?script=sci_arttext\&pid=S244849112016000200051\&lng=es\&tlng=es>. Última consulta: 19 de abril de 2017.

Lucio, R., Villacrés, N., \& Henríquez, R. (2011). Sistema de salud de Ecuador. Salud pública de México, 53 (2), S177-S187. En: <http://www.redalyc.org/articulo.oa?id=10619779013>. Última consulta: 06 de abril de 2017.

Martínez, M. (1999). Comprensión de la cultura no ciudadana en Chile. En, Ciudadanía en Chile: el desafío cultural del nuevo milenio (9-24). Santiago de Chile, Chile: División de Organizaciones Sociales.

Martínez, M., Silva, C., \& Hernández, A. (2010). ¿En qué Ciudadanía Creen los Jóvenes? Creencias, Aspiraciones de Ciudadanía y Motivaciones Para la Participación Sociopolítica. Psykhe, 19 (2), 2537. En: <http://www.redalyc.org/articulo.oa?id=96715366004>. Última consulta: 11 de marzo de 2017.

Pastor, C. (2013). Jóvenes en la política. Agora Política, (7), 48-52. En:<http://www.oldsite.idea.int/americas/ecuador/upload/\%C3\%81gora-Pol\%C3\%ADtica7.pdf>. Última consulta: 06 de marzo de 2017.

Programa de Naciones Unidas para el Desarrollo del Perú (PNUD). (2008). Los jóvenes en el Perú: La democracia imaginada. Lima, Perú: Serie de Desarrollo Humano 14 PNUD. En: <http://onu.org.pe/temas/la-juventud/los-jovenes-en-el-peru-la-democracia-imaginada>. Última consulta: 05 de abril de 2017.

Ramos, G., \& Escobar, C. (2009). Jóvenes, ciudadanía y participación política en México. Estudios Públicos, 12 (25), 103-122. En: <http://www.redalyc.org/articulo.oa?id=67611350007>. Última consulta: 13 de abril de 2017.

Ruiz, J. (2015). El impacto de los medios de comunicación sobre la definición del voto de los ciudadanos de Monterrey en las elecciones presidenciales de 2012. Revista mexicana de ciencias políticas y sociales, 60 (225), 211-232. En: <http://www.redalyc.org/pdf/421/42141200008.pdf>. Última consulta: 01 de abril de 2017.

Santillán, J. (2012). Comunicación y representación política. Razón y palabra, 80, 1-25. En: <http://www.redalyc.org/pdf/1995/199524700035.pdf>. Última consulta: 25 de febrero de 2017.

Secretaría Nacional de Planificación y Desarrollo (SENPLADES). (2011). Tendencias de la participación ciudadana en el Ecuador. Quito, Ecuador: SENPLADES. En: <http://www.planificacion.gob.ec/wpcontent/uploads/downloads/2012/08/Tendencias-de-la-Participaci\%C3\%B3n-Ciudadana-en-elEcuador.pdf>. Última consulta: 03 de marzo de 2017.

Vera, J. (2005). Medios de comunicación y socialización juvenil. Revista de estudios de juventud, (68), 1931. En: <http://www.injuve.es/sites/default/files/revista68_indiceytema.pdf>. Última consulta: 04 de abril de 2017. 
Villa, N. (2012). Televisión, jóvenes y políticas públicas. Aspectos clave de una relación que contribuye al desarrollo social. Eticanet, $12 \quad$ (1), 1 . En: <http://www.ugr.es/ sevimeco/revistaeticanet/numero12/Articulos/Formato/articulo1.pdf>. Última consulta: 30 de marzo de 2017.

Viteri, G. (2007). Situación de la salud en el Ecuador. Observatorio de la Economía Latinoamericana, (77), 1-5. En: <http://www.eumed.net/cursecon/ecolat/ec/2007/gvd-salud.htm>. Última consulta: 18 de abril de 2017.

Yanes, R. (2007). La comunicación política y los nuevos medios de comunicación personalizada. Ámbitos, (16), 356-365.En: <http://www.redalyc.org/articulo.oa?id=16801620>. Última consulta: 03 de abril de 2017.

Zarzuri, R. (2008). Jóvenes, violencia y medios de comunicación. Revista da Associação Nacional dos Programas de Pós-Graduação em Comunicação, 11 (3), 1-23. En: <http://www.compos.org.br/seer/index.php/e-compos/article/viewFile/327/303>.Última consulta: 06 de abril de 2017. 